\title{
LA RUPTURA DE UNA ECONOMÍA MORAL Y LA DESLEGITIMACIÓN DE LAS DEUDAS HIPOTECARIAS
}

\author{
Irene Sabaté Muriel ${ }^{1}$ \\ Universitat de Barcelona
}

\author{
http://dx.doi.org/10.5209/rev NOMA.2016.v47.n1.52399
}

\begin{abstract}
Resumen.- En España, durante la burbuja inmobiliaria reciente, la compra parecía la estrategia más ventajosa de aprovisionamiento de vivienda, y existía un consenso acerca de la inevitabilidad del endeudamiento hipotecario. Pero ese consenso se ha resquebrajado con la crisis financiera e inmobiliaria. Los afectados por las ejecuciones hipotecarias han visto transgredidos principios morales como la justa compensación por el esfuerzo y el sacrificio, la priorización de la satisfacción de necesidades básicas sobre las obligaciones de tipo financiero, la posibilidad de una segunda oportunidad vital para los sobreendeudados, o la responsabilidad estatal de garantizar el sustento de los ciudadanos. Estos principios pueden entenderse como constituyentes de una economía moral cuya ruptura ha contribuido a la aparición de un movimiento social, la Plataforma de Afectados por la Hipoteca (PAH), que pone en cuestión la legitimidad de la deuda hipotecaria. En vista de esto, nos preguntamos en qué medida la percepción del sobreendeudamiento y los desahucios como situaciones injustas, puede tener efectos sobre la reproducción del sistema político-económico, en la medida en que este se perciba como capaz o incapaz de reparar esa injusticia.
\end{abstract}

Palabras clave: Sobre-endeudamiento - Ejecuciones hipotecarias - Crisis económica, financiera e inmobiliaria - Economía moral - Justicia y legitimidad

\begin{abstract}
In Spain, during the recent housing bubble, purchasing a home seemed the most advantageous strategy to access housing, and there was a wide social consensus about the unavoidability of mortgage indebtedness. However, such consensus has been challenged by the financial and real-estate crisis. The victims of home repossessions have been affected by the transgression of several principles, such as the fair compensation for effort and sacrifice, the prioritisation of basic needs over financial commitments, the possibility of a second chance for over-indebted people, or the State's responsibility to guarantee its citizens' livelihood. Such principles may be understood as part of a moral economy, and their transgression has resulted in the emergence of a social movement, the Plataforma de Afectados por la Hipoteca (PAH), that is questioning the legitimacy of mortgage debts. The article reflects on the extent to which the perception of over-indebtedness and evictions as unfair situations can have an effect on the reproduction of the political-economic system, insofar the latter is perceived as able or unable to repair injustice.
\end{abstract}

Keywords: Over-indebtedness - Home repossessions - Economic, financial and real-estate crisis - Moral economy - Justice and legitimacy

${ }^{1}$ [Investigación financiada por la Wenner Gren Foundation (Post-PhD Grant 2014) y la Generalitat de Catalunya (ayudas para Grupos de Investigación Consolidados - GRC 2014 concedida al Grup d'Estudis sobre Reciprocitat de la Universitat de Barcelona)]

(C) EMUI Euro-MediterraneanUniversityInstitute | Universidad Complutense de Madrid | ISSN 1578-6730 Asociada a Nomads. MediterraneanPerspectives | EMUI_EuroMedUniversitySalento | ISSN 1889-7231 
Nómadas. Revista Crítica de Ciencias Sociales y Jurídicas | 47 (2016.1)

(C) EMUI Euro-MediterraneanUniversityInstitute | Universidad Complutense de Madrid | ISSN 1578-6730 Asociada a Nomads. MediterraneanPerspectives | EMUI_EuroMedUniversitySalento | ISSN 1889-7231 


\section{Las economías cotidianas y el sentido de (in)justicia}

Entre 2007 y el segundo trimestre de 2015 se iniciaron en España 642.104 ejecuciones hipotecarias, según el Consejo Superior del Poder Judicial. En el período entre 1998 y 2008, el endeudamiento de los hogares españoles se incrementó en un 45,5\% (Dubois y Anderson, 2010). El endeudamiento de los hogares alcanzó un punto álgido en 2010, cuando suponía un $84,7 \%$ del PIB, casi el doble que una década antes: en el año 2000 era del 43,6\% (Fuente: EUROSTAT y Banco de España). Estas cifras tan considerables, indicadores de un problema social acuciante, vienen atrayendo la atención de expertos, legisladores y activistas.

Desde un punto de vista antropológico, el fenómeno de la morosidad hipotecaria puede interpretarse como una transgresión -a escala masiva y bajo fuertes determinantes económicos- de la obligación de devolver que está implícita en las relaciones de deuda y crédito (Graeber, 2011). Esto implica un conflicto con la rígida especificación de los términos de la devolución en el capitalismo financiero (Guyer, 2012), que sólo contempla la refinanciación pero no la condonación (Stout, 2015), y parece estar contrarrestando la previa invisibilidad social de la insolvencia.

Entre las muchas cuestiones suscitadas por esta situación, el presente artículo se centrará en cómo la percepción del (sobre)endeudamiento, y un creciente sentimiento de injusticia acerca de esta condición en el contexto histórico de una crisis económica, lleva a las personas a atribuir nuevos valores y significados a las prácticas económicas cotidianas, desafiando las representaciones ortodoxas de la provisión habitacional y de los productos financieros. El artículo considerará también la transformación de la secuencia temporal que habitualmente se asocia a los ciclos domésticos y los proyectos de vida en circunstancias más prósperas, como resultado de una incertidumbre sostenida en el tiempo a causa de la debacle económica y financiera. Tal incertidumbre puede deberse al desempleo, la precariedad laboral, al sobre-endeudamiento, a la presión de las dificultades económicas sobre los lazos sociales, o a otras circunstancias adversas.

Así, analizaremos la articulación cambiante entre, por un lado, los modelos y prescripciones de la teoría económica hegemónica, y, por otro lado, las actitudes de los deudores hipotecarios -y de quienes simpatizan con ellosdurante una ruptura del crecimiento capitalista. Lo que sigue es, por tanto, un intento de interpretar el grado en que los deudores hipotecarios han modificado sus asunciones acerca de la economía, y, en consonancia con ello, han repensado sus proyectos de vida debido a la experiencia de la crisis. Utilizaremos la noción de economía moral (Thompson, 1976; Scott, 1976) para explicar la reacción social contra el sobre-endeudamiento hipotecario -una condición que se percibe cada vez más como ilegítima- y contra la ola de desahucios -percibida como una injusticia. Pero también consideraremos las continuidades de la conformidad social con la ortodoxia económica, basada en la expectativa de la recuperación económica. 
El objetivo principal del artículo será, pues, analizar la indignación y frustración (Scott, 1976:188) causadas por la percepción del sobre-endeudamiento hipotecario como una condición ilegítima, producto de la violación de principios de economía moral ampliamente compartidos por las personas endeudadas y, de modo creciente, por la sociedad en su conjunto.

\section{Asunciones comunes durante la burbuja inmobiliaria}

Durante la burbuja inmobiliaria española más reciente, finalizada en 2007 (Naredo, 2009), el acceso al crédito apenas presentaba restricciones para gran parte de la población, independientemente de su solvencia financiera. Durante aquellos 'buenos tiempos', las posibles fuentes de incertidumbre económica apenas se tenían en cuenta. Se esperaba que los tipos de interés se mantuvieran bajos, y los empleos temporales -millones de ellos en el sector de la construcción- eran percibidos como estables. Además, una porción importante de los trabajadores asalariados confiaban en las horas extra para mantener el nivel de ingresos que tenían en aquel momento.

En un ambiente así de optimista, muchas asunciones dominantes acerca del significado de la acción económica, originadas por expertos económicos y legisladores, parecían ser ampliamente compartidas por los legos. Por ejemplo, en el ámbito de la vivienda, la preferencia por la propiedad frente al alquiler era muy marcada. Llegar a ser propietario -normalmente gracias a una hipoteca a devolver en treinta o incluso cuarenta años- era considerado comúnmente como la estrategia más sensata para las familias que necesitaban una vivienda (López y Rodríguez, 2010). Lejos de considerarse como el resultado de un deseo frívolo (James, 2010), la acción de endeudarse se naturalizaba como el único modo de hacer una inversión a largo plazo en la vivienda, mientras que pagar un alquiler a cambio de un alojamiento se consideraba equivalente a tirar el dinero, por más que ambas estrategias pudieran dar acceso a valores de uso similares, y que, por tanto, pudieran satisfacer necesidades similares en el presente, aunque fuera con implicaciones distintas a medio y largo plazo.

Lejos de ser resultado de una presunta "cultura hispánica de la propiedad", la preferencia por esta forma de tenencia se debe a circunstancias estructurales que pueden rastrearse hasta el período franquista (Naredo, 2011; Idoate et al, 2008; Palomera, 2014). En efecto, los comportamiento de compra y de contratación de préstamos hipotecarios eran promovidos activamente por las instituciones financieras y por los agentes inmobiliarios, como también por las disposiciones fiscales, además de ser compartido por los ciudadanos corrientes, que a su vez contribuían a ejercer presión sobre sus iguales (James, 2012). La vivienda de propiedad aparecía como la materialización del bienestar de la familia. Y esto no solo era válido por los españoles autóctonos: también para los varios millones de migrantes llegados recientemente al país, la compra de un hogar implicaba la promesa de la incorporación a la sociedad de acogida, pese a la fuerte discriminación con la que topaban en el mercado inmobiliario (Martínez Veiga, 1999). Además, para una amplia clase media, el creciente 
valor económico de las propiedades las convertía en un objeto de inversión lucrativa, en contraste con el descenso de los salarios reales ocurrido durante la historia reciente. El crédito permitía así el consumo en lo inmediato, además de una supuesta movilidad social ascendente de cara al futuro.

Detallemos a continuación algunas de las asunciones populares que concordaban con la ortodoxia neoliberal. En primer lugar, los actores económicos -ya sean individuos o unidades domésticas- se representaban como agentes autónomos que participaban en las transacciones libremente y en pos del propio interés. Se desenfatizaban los constreñimientos sociales, culturales e históricos de las prácticas económicas, en beneficio de explicaciones individuales de esas prácticas como resultado de elecciones, decisiones, la oferta y la demanda o la negociación. Por ejemplo, los bancos aparentaban dar el mismo trato a todos sus clientes en tanto que tales actores individuales, cuando, en realidad, su posición social era un criterio crucial para determinar las condiciones en que obtenían acceso al crédito.

Segundo, una ética del trabajo y la industriosidad justificaba los sacrificios que debían hacerse tanto en el trabajo como en el ámbito doméstico, en las esferas productiva y reproductiva, para conseguir mejores condiciones de vida. Esta ética resultaba especialmente llamativa entre los migrantes, que aceptaban duras condiciones de vida y trabajo, y que veían el endeudamiento como la condición inevitable para alcanzar los estándares de consumo locales.

En tercer lugar, se esperaba que la gente corriente invirtiera, se arriesgara y se endeudara, tal y como haría un empresario, para llevar a cabo sus proyectos de vida. Se consideraba que era un buen momento para invertir en propiedad inmobiliaria, dado que los precios parecían incrementarse indefinidamente y que, también en apariencia, la inversión podía recuperarse en cualquier momento mediante la liquidación del activo. De este modo, la vivienda se presentaba como una inversión flexible en el tiempo, dado que la liquidez parecía estar garantizada por su valor en aumento. En este aspecto se producía también una considerable presión social, con el resultado, por ejemplo, de que muchas parejas jóvenes compraban pisos pequeños con las expectativa de cambiarlos por otros más grandes al cabo de pocos años, cuando decidieran tener descendencia.

En cuarto lugar, el progreso material, en forma de un aumento del consumo, se identificaba con la representación social de una vida mejor, a menudo en comparación con el estándar alcanzado por las generaciones anteriores. Se esperaba experimentar ese progreso material -unido a un ascenso social- en los primeros años del ciclo doméstico. La memoria social y familiar, en este sentido, constituía también un incentivo para la contratación de préstamos hipotecarios. Esto se ilustra en el desplazamiento de muchas familias jóvenes desde los polígonos de vivienda o los barrios urbanos donde habían crecido hacia emplazamientos periurbanos donde podían permitirse comprar una casa unifamiliar en lugar de un piso. En algunos casos el importe prestado con la hipoteca excedía incluso el precio del inmueble, con lo que se pretendía cubrir gastos adicionales como la compra de muebles, electrodomésticos 0 
automóviles, bienes que podían cumplir una función de consumo conspicuo.

Quinto, la práctica lucrativa del crédito se legitimaba como una condición esencial para la prosperidad de la economía. Se veía a los bancos como proveedores de una suerte de servicio público, dado que proporcionaban crédito a empresarios y consumidores, en un momento caracterizado por la buena marcha de los negocios, y en que devolver las deudas no parecía problemático, al tiempo que el crecimiento económico se veía como equivalente al bien común. La lógica maximizadora que guiaba la acción de los bancos resultaba casi invisible, especialmente en el caso de las cajas de ahorros, instituciones financieras estrechamente vinculadas con las autoridades locales y regionales que, en efecto, habían sido concebidas en términos de servicio público, para luego perder esta inspiración a finales del s.XX. Sus vínculos con áreas geográficas específicas -cada vez más imaginados que reales-, así como las actividades filantrópicas que fomentaban desde sus fundaciones, explican también su popularidad y la falta de cuestionamiento sobre su comportamiento.

En sexto lugar, la devolución de las deudas se entendía como una prioridad dentro de los presupuestos domésticos, y quienes no cumplían con esta obligación eran objeto de reprobación moral. De hecho, antes de la proliferación de las ejecuciones hipotecarias, los deudores hipotecarios en mora estaban completamente ausentes de la escena pública, y constituían un sector invisible de la sociedad española: el suyo era un problema para sufrir en soledad (James, 2012:22, nuestra traducción). O bien, cuando aparecían en los medios de comunicación, se les representaba como pertenecientes a grupos marginales. Mientras tanto, los grupos domésticos que comenzaban a tener problemas para pagar sus cuotas continuaban viendo sus obligaciones financieras como una prioridad absoluta $y$, en consecuencia, trataban de afrontarla reorganizando y recortando sus gastos, al menos durante el período en que tales medidas de austeridad resultaban todavía sostenibles (Sabaté, 2015b).

Y, finalmente, durante la burbuja inmobiliaria, estaba muy extendida la representación de la vivienda como una mercancía, incluso entre los grupos domésticos que sólo poseían una primera residencia. Si bien la mayor parte de los compradores tenían intención de habitar sus viviendas, una porción importante de la clase media vio la posibilidad de invertir en segundas residencias, confiando en el tiempo como un factor que les proporcionaría un margen de beneficio.

Se puede afirmar que, antes de 2007, este conjunto de creencias y representaciones era compartido no sólo por los expertos -que producen la 'verdad' acerca de la economía-, autoridades públicas -que promueven ciertos comportamientos a través de políticas y regulaciones- y profesionales del sector inmobiliario, sino también por amplias capas de la sociedad española, que no sólo no las cuestionaban, sino que tendían a reforzarlas y amplificarlas. Por más que la mayoría de familias tuvieran que destinar gran parte de sus ingresos a las cuotas hipotecarias, el sacrificio se percibía como útil y necesario 
a largo plazo, dado que les proporcionaba el sentido de estabilidad y prosperidad asociado con la propiedad de la vivienda.

\section{Crisis hipotecaria, descontento social y emergencia de un movimiento social}

Desde 2008, con la irrupción de la crisis económica, esta situación ha cambiado dramáticamente (Naredo, 2009). Debido sobre todo al desempleo masivo y al endeudamiento creciente de los hogares españoles, la devolución de los préstamos hipotecarios se ha convertido para muchos en una preocupación. Cada vez más gente se ha visto incapaz de afrontar las cuotas, y también de acceder como alternativa a una vivienda de alquiler, dado que el mercado de alquiler es altamente discriminatorio, el parque de viviendas continúa siendo escaso y caro, la vivienda social de alquiler es casi inexistente en España, y las personas que figuran en listas de morosos no son aceptadas como inquilinos por los arrendadores privados. Su acceso a un cobijo, sea cual sea la forma de tenencia, se encuentra pues en peligro.

Junto a estas consecuencias materiales, la crisis también ha tenido un impacto sobre el modo en que las personas perciben sus posibilidades de obtener un sustento. Al revelarse como falsas las promesas de ascenso social, las actuales aspiraciones de muchos grupos domésticos se limitan a la conservación de los estándares de vida adquiridos con anterioridad, incluyendo las condiciones de habitación. En algunos casos es forzoso incluso abandonar esta aspiración. Es entonces cuando los grupos domésticos se ven abocados a aplicar únicamente estrategias a corto plazo, dado que cualquier planificación del futuro se encuentra fuera de su alcance. Los ejemplos más significativos implican involuciones en la temporalidad esperada de los ciclos domésticos, como cuando familias con niños que se ven obligadas a cobijarse en casa de los abuelos, o cuando los migrantes se ven forzados a regresar a sus países de origen.

En efecto, verse incapaz de pagar la hipoteca es una de las circunstancias más indeseables que puede afrontar una unidad doméstica, dado que la perspectiva de perder el hogar amenaza también gravemente la reproducción doméstica y social (Carrier y Heyman, 1997). Esto explica por qué este tipo de situaciones resultan de entrada impensables. En caso de ejecución hipotecaria, los deudores no sólo temen quedarse sin techo, sino también ser culpados de su propia situación (Graeber, 2011) y estigmatizados como perdedores en la vida (James, 2012). Abundan las acusaciones de haber vivido "por encima de sus posibilidades" y la condena del consumo excesivo o de la codicia por objetos materiales, entre ellas las propiedades inmobiliarias. Las evaluaciones negativas acerca del comportamiento pasado, que hoy se tacha de irresponsable, se combinan con situaciones presentes de insolvencia que impiden cualquier intento de hacer proyectos de futuro.

Hasta hoy, mientras el número de ejecuciones hipotecarias continúa 
aumentando, los legisladores y las autoridades públicas han hecho poco ante el problema y, más en general, ante las consecuencias de la crisis económica española sobre la provisión habitacional. En marzo y noviembre de 2012, se promulgaron dos decretos que consistían meramente en sugerir "buenas prácticas" a las entidades financieras, y que sólo han beneficiado a una pequeña minoría de deudores hipotecarios. En la actitud de los jueces se observan cambios más significativos. Algunos de ellos han apoyado en sus sentencias la causa de los deudores, mediante argumentos variados: la ilegalidad de la legislación hipotecaria española de acuerdo con los estándares de la UE, la falta de transparencia o incluso el carácter fraudulento de los contratos, la vulneración de los derechos de los consumidores, la dimensión social y humana del problema, etc. También algunas instituciones europeas, como el Tribunal de Estrasburgo, se han pronunciado en este sentido, así como algunos gobiernos extranjeros como el de Ecuador, cuyos nacionales constituyen uno de los colectivos más afectados. Además, ciertos profesionales implicados en las ejecuciones y los desahucios -jueces, notarios, fiscales, bomberos, agentes de policía, algunos alcaldes...- se han opuesto a su implementación objetando conflictos de conciencia.

De forma paralela, sólo se han hecho intentos aislados de procesar a ejecutivos de la banca por sus prácticas fraudulentas, mientras la opinión pública asiste repetidamente a las noticias sobre los suicidios de morosos hipotecarios. La indignación popular también se ha desencadenado ante los rescates bancarios con dinero público, y ante el procesamieto de personas famosas, incluyendo algunos miembros de la familia real, por sus prácticas corruptas, que en ocasiones implican la especulación inmobiliaria y el trato de favor por parte de instituciones financieras.

Esta indignación popular ha cristalizado en parte en un movimiento social, la Plataforma de Afectados por la Hipoteca, fundada en 2009 para representar los intereses de los hogares que se encuentran con dificultades para pagar sus hipotecas. La actividad de la PAH tiene una doble veriente. Por un lado, proporciona apoyo a los casos individuales en asambleas locales de frecuencia semanal, en las que los deudores reciben asesoramiento de cara a la negociación con el banco. Las aproximadamente doscientas asambleas locales de la PAH presionan también a empleados de banca y representantes públicos específicos, y convocan movilizaciones para evitar desahucios de viviendas concretas, así como otras acciones directas en lugares como oficinas bancarias, agencias inmobiliarias, dependencias de los servicios sociales, ayuntamientos, espacios públicos... Por otro lado, la PAH fomenta una acción política que influya en la opinión pública y reclame la intervención de legisladores, jueces y otras autoridades públicas. En este sentido, además de sus llamadas a la protesta, la $\mathrm{PAH}$ ha promovido varias iniciativas legislativas populares (ILP), como la que en 2013 forzó al Parlamento español a debatir una reforma legal que liberaría a las familias de su deuda a través de la dación en pago y que les proveería una vivienda alternativa, o bien la permanencia en la misma vivienda a cambio de un alquiler asequible. Si bien la iniciativa topó con la oposición de una mayoría parlamentaria, logró reunir los apoyos de más de 500.000 
personas y, durante la campaña de presión a los representantes parlamentarios que se manifestaron en contra de la iniciativa (los llamados escraches), dio una visibilidad sin precedentes al problema de las ejecuciones.

Además de lo anterior, la PAH también ha promovido la ocupación de edificios residenciales vacíos, propiedad de entidades bancarias, para dar alojamiento a familias ya desahuciadas. En suma, las actividades de la PAH -sean negociaciones con los bancos, movilizaciones colectivas o eventualmente la ocupación de viviendas- pueden interpretarse como la exigencia de una respuesta a los problemas de los grupos grupos domésticos para continuar procurándose un sustento y obtener una segunda oportunidad tras el impago.

\section{Cuestionando la hegemonía de la ortodoxia económica}

Sostenemos que circunstancias históricas como una crisis financiera tienen el potencial de cuestionar la hegemonía de los modelos expertos y los significados comúnmente atribuidos a las prácticas económicas. En efecto, varios síntomas indican que puede estar extendiéndose una nueva atmósfera social que podemos identificar como una re-emergencia de principios de economía moral, un concepto definido originalmente por Thompson (1971) cuando analizó el resentimiento popular (1971:87) contra nuevas prácticas de mercado en la Inglaterra del s. XVIII, y que fue luego revisado por Scott (1976) para dar cuenta de las tensiones provocadas por las nuevas formas de dominio y subordinación económica en las sociedades campesinas del Sur de Asia.

¿En qué consiste esta economía moral que parece re-emerger en el caso español? Para empezar, se observan cambios a gran escala, tales como una mayor conciencia de las dimensiones colectivas y sociales del sobre-endeudamiento, que ha reemplazado una situación anterior en la que los morosos hipotecarios eran socialmente invisibles. Las hipotecas, y la incapacidad de pagarlas, ya no son meramente una cuestión de comportamiento o de elección individual, sino que implican a los grupos domésticos en su conjunto, incluyendo a los niños y personas dependientes. Se reconoce así que los actores económicos no son individuos libres, sino personas con obligaciones y responsabilidades hacia otras personas, lo cual constriñe su libertad de elección, especialmente en circunstancias de desempleo, enfermedad, o disminución de los ingresos.

En este nuevo estado de opinión, aumenta la reclamación de un "precio justo" para la vivienda, tras los años de rápida revalorización de las propiedades inmobiliarias. En el caso de los hogares que se enfrentan con la amenaza del desahucio, la PAH y otras organizaciones animan a negociar un "alquiler social" -en el sentido de asequible, proporcionado con los ingresos disponibles- en el amplio parque de viviendas propiedad de los propios bancos.

Esto conecta también con el extendido sentimiento de indignación frente al rescate bancario -en lugar del "rescate" de los ciudadanos. El agravio causa una falta de confianza en el rol del Estado como garante del bienestar social, y 
despoja al mercado de su previa representación como un mecanismo justo para distribuir los recursos, dado que las entidades financieras han requerido inyecciones de dinero público para evitar la bancarrota.

Parte de la opinión pública formula también una condena de la especulación y el enriquecimiento, clamando en contra del fraude y de los préstamos abusivos, y a favor de la honestidad en el comportamiento económico. Los discursos populares y los movimientos sociales reclaman la identificación y el procesamiento de los responsables de la ola de ejecuciones hipotecarias. De momento, los pocos procesos iniciados se interpretan como productos de la obstinación de algún juez, más que como una lucha sistemática contra la mala praxis bancaria, lo cual impide la restauración de la justicia a escala de la sociedad en su conjunto.

Hoy se cuestiona el papel de los banqueros -a quienes no se exige responsabilidades- y de los políticos -que se muestran insensibles ante las necesidades sociales y cómplices de intereses privados- como contribuidores al bien común. Se les ve más bien como parásitos, como individuos pertenecientes a una misma élite y guiados por la búsqueda de su propio provecho. Esta condena se extiende a cualquiera que colabore con las actividades bancarias, incluidos los empleados de banca que se aprovecharon de la confianza de sus clientes para venderles productos financieros arriesgados.

En este ambiente, los afectados por relaciones deudor-creditor abusivas que se incorporan a movimientos sociales como la $\mathrm{PAH}$ van adquiriendo un sentimiento de unión. Se sienten "empoderados" y determinados a luchar por sus familias. Compartiendo información y practicando la empatía, superan su anterior aislamiento. Muchas personas sin experiencia activista previa viven una transformación que incrementa la seguridad en sí mismos y les hace capaces de enfrentarse con los empleados de banca y con los representantes del Estado. También afirman haber adquirido conciencia de sus derechos, incluidos los aspectos técnicos, y han adquirido otras habilidades relacionadas, como la capacidad de hablar en público acerca de sus casos.

Finalmente, la acción colectiva que perturba el orden público resulta legitimada hasta cierto punto. Por parte de la PAH, las movilizaciones -no violentas pero muy llamativas- y un uso hábil de los medios de comunicación y de Internet han retroalimentado este estado de opinión. Especialmente a escala de los barrios y los vecindarios, tales "disrupciones" han contribuido a romper el silencio en torno a las deudas hipotecarias, y a atraer el apoyo de los vecinos, parientes, conocidos, compañeros de trabajo, etc. Resulta especialmente intersante el hecho de que muchos protagonistas de tales disrupciones del orden público no experiencia previa de activismo, sino que más bien están expresando su indignación de manera espontánea, aunque casi siempre dentro de los límites marcados por los protocolos de acción coordinada y no violenta de la PAH.

Junto a estos cambios en la opinión pública, que han reforzado y derivado de nuevas modalidades de acción colectiva, se pueden observar también transformaciones importantes a escala doméstica. En este ámbito, la obligación 
de pagar las cuotas hipotecarias se ve cuestionada por la priorización de la satisfacción de otras necesidades básicas. Cuando las personas entran en mora, alimentarse y alimentar a los dependientes resulta prioritario, mientras que seguir pagando una deuda que nunca podrá saldarse puede perder su sentido. De hecho, la legislación que limita el embargo de los ingresos de los deudores por parte de los creditores, estableciendo un "mínimo inembargable" que en teoría salvaguarda su sustento -independientemente de que ese mínimo sea efectivamente suficiente- puede entenderse como la cristalización legal de este principio. No obstante, este mínimo no garantiza el acceso a una vivienda alternativa, ya que los deudores aparecen en listas de morosos que les dificultan el acceso a un piso de alquiler.

En el caso de algunos migrantes, que según fuentes de la propia PAH constituyen un tercio de la población afectada por la morosidad hipotecaria (Colau y Alemany, 2012), la posibilidad de escapar a la obligación de devolver el préstamo volviéndose al país de origen puede verse hasta cierto punto legitimada como una estrategia defensiva, en lugar de ser condenada como una irresponsabilidad.

También se ha producido una inflexión en las expectativas y planes vitales de las personas. El énfasis recae ahora en la conservación de los estándares de vida, o en la supervivencia en los casos más dramáticos, más que en el progreso económico entendido como un aumento del consumo. Con este objetivo se moderan los gastos monetarios, se practica la ayuda mutua y los favores en lugar de la compra en el mercado, se cohabita como estrategia para la reducción de gastos, o se recurre a instituciones caritativas (Sabaté, 2014).

La reclamación de una segunda oportunidad vital, propiciada por la cancelación de la deuda tras la pérdida de la vivienda, también se escucha a menudo de boca de los deudores y de quienes les apoyan. La dación en pago es probablemente la reclamación más popular de la $\mathrm{PAH}$, tal y como se ha revelado en el amplio apoyo a la ILP. Aunque se reconozcan errores pasados, existe ahora consenso acerca de que los deudores deberían tener oportunidad de rehacer sus vidas y sus proyectos, una oportunidad negada si el sobre-endeudamiento se perpetúa.

\section{Continuidades de la conformidad con las nociones hegemónicas de la economía}

No obstante, la re-moralización de las prácticas y discursos económicos que acabamos de describir no implica una subversión total de las concepciones anteriores sobre las prácticas económicas bajo el capitalismo financiero, como por ejemplo la provisión habitacional o el crédito hipotecario. Por el contrario, se han preservado hasta hoy algunos elementos de la ortodoxia económica, y esa continuidad pone en duda que esta crisis vaya a suponer una ruptura histórica. De hecho, las relaciones entre creditores y deudores, así como el modo en que los grupos domésticos se enfrentan al sobre-endeudamiento, 
siguen viéndose influidos por un cierto grado de conformidad social con la hegemonía neoliberal.

Tales continuidades resultan evidentes, por ejemplo, cuando los deudores afirman su voluntad de pagar la deuda y justifican su incapacidad para hacerlo por su falta de ingresos. De ese modo están en realidad reafirmando la obligación de devolver, a no ser que exista una imposibilidad absoluta. Esta actitud también está presente cuando los deudores en mora afirman su "buena fe" en contraste con otras personas que, según ellos, están aprovechándose de la ola de ejecuciones para eludir sus responsabilidades y obtener fácilmente una dación en pago o una condonación de la deuda.

Por otra parte, para muchos deudores que ya han sufrido el desahucio, volver a la condición de inquilinos se entiende como un paso atrás en sus trayectorias que subvierte la secuencia temporal esperada: vivir temporalmente de alquiler -situación indeseable- para luego devenir propietarios -situación deseable. Especialmente en el caso de los migrantes, dado que la propiedad inmobiliaria implicaba una promesa de incorporación a la sociedad de acogida además de un progreso socioeconómico, la pérdida de la propiedad y el regreso al mercado de alquiler, a menudo en condiciones discriminatorias, se experimenta como un fracaso del proyecto migratorio. $Y$ también para las familias autóctonas se perturba el ciclo doméstico cuando se ven forzados a volver a alojarse en casa de la generación anterior.

También es común que los deudores recurran a estrategias mercantiles individuales cuando ven la amenaza del impago. Por ejemplo, pueden intentar la negociación individual con el banco, o pueden tratar de vender el inmueble de manera ventajosa, o alquilarlo total o parcialmente. Estos deudores en apuros, lejos de cuestionar la lógica capitalista, permanecen dentro de sus límites, tratando de maximizar la utilidad en operaciones de mercado, a pesar de su posición de desventaja.

También en muchos casos, los deudores en mora, así como otros protagonistas de las relaciones de crédito como los empleados de banca, aceptan -0 al menos no cuestionan- las atribuciones de reponsabilidad individual. Para ellos, las hipotecas siguen siendo contratos en los cuales ambas partes participaron libremente, y no se tienen en cuenta factores estructurales o contextuales que matizarían esta afirmación. Un comentario muy recurrente en este sentido es el de que "nadie te puso una pistola en la cabeza para que firmaras". Como consecuencia, no es inusual que los deudores se avergüencen y se sientan poco identificados con las respresentaciones comunes acerca de cómo deberían gestionarse las economías domésticas. Esto es lo que ocurre a veces en el caso de las parejas y otros parientes cercanos de personas que acuden a la $\mathrm{PAH}$ : si bien están también amenazados por el desahucio, la vergüenza les impide acudir a las asambleas y reconocer en público su problema.

En suma, la reproducción del sistema económico y de la ideología que lo sustenta se apoya en estas continuidades de la conformidad social con la ortodoxia económica, así como en la esperanza de la recuperación económica, 
ya sea a escala macrosocial como consecuencia de la restauración de un ciclo de crecimiento, ya sea a escala doméstica gracias a un cambio de la suerte individual.

\section{La crisis hipotecaria española y la violación de principios de economía moral}

El aspecto de la teoría de Thompson que puede aplicarse a nuestro caso es el de la reclamación popular de una re-moralización del comercio y el consumo en una época de cambios históricos rápidos, en la que la financialización de las economías domésticas y del aprovisionamiento de vivienda (Aalbers, 2008) está subvirtiendo la anterior comprensión de las prácticas económicas y, más concretamente, de las relaciones de deuda y crédito. Esperamos haber ilustrado esta idea en la cuarta sección de este artículo, al detallar el conjunto de consideracions morales que han aumentado su peso en las representaciones populares del sobre-endeudamiento hipotecario y la ola de ejecuciones.

En este apartado final, seguiremos la propuesta de Scott (1976) para interpretar la reacción popular contra los desahucios como el resultado de una transgresión percibida de la norma de reciprocidad, entendida como un desequilibrio en el intercambio -entre deudores y creditores- y en una amenaza para el derecho a la subsistencia.

Pero, antes de desarrollar más nuestros argumentos, debemos admitir que, al inspirarnos en las nociones de economía moral de Scott y Thompson, no deberíamos pasar por alto las diferencias entre las situaciones históricas consideradas por ellos y la que estudiamos aquí. En nuestro caso, los actores se encuentran ante los ciclos cambiantes del capitalismo financiero, caracterizados por la inestabilidad, la incertidumbre y la falta de una tradición fuerte delineando una economía moral. Esto es así especialmente para los migrantes que se enfrentan por primera vez con el Estado y las entidades financieras españolas. A diferencia de los casos de la multitud inglesa de Thompson o del campesinado sudasiático de Scott, no encontramos aquí una larga historia de relaciones con unas élites locales conocidas. Por el contrario, para la mayoría de las personas, el sobre-endeudamiento y las ejecuciones hipotecarias son consecuencias de un encuentro sin precedentes con fuerzas impersonales: las de las instituciones financieras y estatales.

Dicho esto, nuestra intención en este artículo ha sido construir la economía moral operacional de una clase subordinada (Scott, 1976:160) en unas circunstancias históricas particulares, como las de la actual crisis hipotecaria en España, para dar cuenta de la indignación y la frustración (Scott, 1976:188) de aquellos que perciben ahora el sobre-endeudamiento hipotecario como una condición ilegítima, resultado de la violación de ciertos principios de economía moral.

En primer lugar, la transgresión de la norma de reciprocidad basada en el (c) EMUI Euro-MediterraneanUniversitylnstitute | Universidad Complutense de Madrid | ISSN 1578-6730 Asociada a Nomads. MediterraneanPerspectives | EMUI_EuroMedUniversitySalento | ISSN 1889-7231 
equilibrio del intercambio (Scott, 1976:167) puede verse aquí en dos sentidos. Por un lado, se ha pervertido la relación comercial entre los bancos y/o empresas inmobiliarias y sus clientes -los deudores hipotecarios y los compradores de viviendas. Por otro lado, también parece haberse violentado la relación de reciprocidad entre las instituciones del Estado de bienestar y los ciudadanos, consistente en un conjunto de derechos y deberes asumidos por estos últimos a cambio de cierta responsabilización del Estado respecto al bienestar social.

Además, el derecho a la subsistencia, entendiendo la subsistencia como el derecho social fundamental (Scott, 1976:176), también se ha erosionado para sectores crecientes de la población. Con la disminución de las oportunidades de procurarse un sustento, el derecho a la subsistencia pasa a estar en peligro $y$, en consecuencia, se revisan las jerarquías de necesidades previamente aceptadas. La obligación de devolver las deudas hipotecarias se ve cuestionada o, cuando menos, pierde su posición destacada entre los gastos de las economías domésticas (Sabaté, 20015a, 2015b).

Hemos comenzado afirmando que, en tiempos de prosperidad, la legitimidad del sistema económico se apoyaba en ciertas asunciones que eran compartidas por amplios sectores de población, tales como el valor otorgado a la propiedad inmobiliaria o la fe en la perpetuación de la revalorización de los activos. En aquellas circunstancias, los sacrificios que pudieran hacerse por conseguir un bien que siempre iba a incrementar su valor valían la pena. En consecuencia, el intercambio -entre compradores y agentes inmobiliarios, entre deudores hipotecarios y entidades financieras- se percibía como equilibrado.

Después, como resultado de la crisis económica y de las experiencias del desempleo masivo y las ejecuciones, estas relaciones de intercambio han sido reevaluadas: un sector considerable de la opinión pública española ha pasado de la legitimación a un sentimiento de explotación, a medida que el endeudamiento hipotecario ha pasado de valorarse como una situación equitativa a verse como una injusticia, un intercambio desigual y abusivo. Lo que se consideraba justo, incluso como beneficioso tanto para individuos específicos como para el bien común, se considera ahora explotador. Se percibe ahora que las condiciones del intercambio violan el "verdadero valor" de las cosas: las tasaciones que durante la burbuja se hacían de los bienes inmobiliarios pasan a considerarse engañosas o directamente falsas. Y esto se da a pesar aún tratándose de contratos a los que se ha consentido libremente (Scott, 1976:164). "Préstamo abusivo" es la etiqueta asignada a las prácticas que, si bien se han producido en un marco contractual, se ven hoy como ilegítimas, más allá de su carácter legal o ilegal. La violación de principios de economía moral, y no necesariamente la violación de la ley, parece ser el rasgo distintivo del endeudamiento ilegítimo.

No obstante, todo esto no tiene por qué implicar un obstáculo importante para la reproducción del sistema capitalista. Si las continuidades de la conformidad social y la esperanza en una restauración del crecimiento económico predominan sobre el desafío que implica un sentimiento popular de injusticia, 
¿qué puede esperarse de un futuro potencial en el que se recuperen la tendencia expansiva del mercado y la disponibilidad del crédito? ¿Puede esperarse un reforzamiento de la conformidad popular con los modelos de la ortodoxia económica? ¿O bien la experiencia de la actual crisis tendrá impacto en las futuras decisiones económicas de los grupos domésticos? Todas estas preguntas han vinculado nuestro análisis de las consecuencias inmediatas del sobre-endeudamiento hipotecario, tanto para los grupos domésticos que sufren las ejecuciones como para la estructura social en general, con las articulaciones pasadas, presentes y futuras entre las economías morales y los modelos de la ortodoxia económica y la práctica cotidiana.

\section{Bibliografía}

Aalbers, M.B. (2008). The financialization of home and the mortgage market crisis. Competition and Change, 12(2), 148-166. doi: 10.1179/102452908X289802

Carrier, J.C.; Heyman, J.McC. (1997). Consumption and political economy. The Journal of the Royal Anthropological Institute, 3(2), 355-373. doi: $10.2307 / 3035024$

Colau, A.; Alemany, A. (2012). Vides hipotecades. De la bombolla immobiliària al dret a l'habitatge. Barcelona: Angle Editorial.

Consejo Superior del Poder Judicial (2015). Efecto de la crisis en los órganos judiciales. $\quad 2^{\circ} \quad$ trimestre 2015, http://www.poderjudicial.es/stfls/CGPJ/ESTAD\%C3\%8DSTICA/DATOS\%20EST AD\%C3\%8DSTICOS/FICHERO/20151013\%20Datos\%20sobre\%20el\%20efect o\%20de\%20la\%20crisis\%20por\%20TSJ\%202T\%202015.xls [28/10/2015].

Dubois, H.; Anderson, R. (2010). Managing household debts: Social service provision in the EU. Working paper, Eurofound project: Managing household debt, http://www.eurofound.europa.eu/pubdocs/2010/70/en/2/EF1070EN.pdf [10-21-2014].

EL PAís (2015, 26 de octubre). La deuda de empresas y familias. Descargado de http://elpais.com/elpais/2015/10/25/media/1445795086 016146.html

Graeber, D. (2011). Debt, The first 5,000 years. New York: Melville House.

Guyer, J. (2012). Obligation, binding, debt and responsibility: provocations about temporality from two new sources. Social Anthropology, 20(4), 491-501. doi: 10.1111/j.1469-8676.2012.00217.x

Idoate, E. et al. (2008). Políticas de vivienda en el Estado Español. Informes de Economía del Seminario de Economía Crítica Taifa, 5, 66-80.

James, D. (2010, $6^{\text {th }}$ October). Debt regulation based on faulty assumptions. Mail \& Guardian Online. Descargado de http://mg.co.za/article/2010-10-06-debt-regulation-based-on-faulty-assumptions 
James, D. (2012). Money-go-round: personal economies of wealth, aspiration and indebtedness. Africa, 82(1), 20-40. doi: http://dx.doi.org/10.1017/S0001972011000714

López, I.; Rodríguez, E. (2010). Fin de ciclo. Financiarización, territorio y sociedad de propietarios en la onda larga del capitalismo hispano (1959-2010). Madrid: Traficantes de Sueños.

Martínez Veiga, U. (1999). Pobreza, segregación y exclusión espacial. La vivienda de los inmigrantes extranjeros en España. Barcelona: Icaria.

Naredo, J.M. (2011) El modelo inmobiliario español y su culminación en el caso valenciano. Barcelona: Icaria.

Naredo, J.M. (2009). La cara oculta de la crisis. El fin del boom inmobiliario y sus consecuencias. Revista de Economía Crítica, 7, 313-340.

Palomera, J. (2014). How Did Finance Capital Infiltrate the World of the Urban Poor? Homeownership and Social Fragmentation in a Spanish Neighborhood. International Journal of Urban and Regional Research, 38(1), 218-235. doi: 10.1111/1468-2427.12055

Sabaté, I. (2014). Del país de los propietarios al país de los sobre-endeudados. Reciprocidad, solidaridad y proyectos de transformación sistémica en tiempos de crisis, Ars \& Humanitas, 8(1), 167-187. doi: 10.4312/ars.8.1.167-187

Sabaté, I. (2015a). To repay or not to repay. Patterns of inequality emerging from mortgage (over-)indebtedness in Spain. Paper presented at the Conference of the ASA, Exeter, $13^{\text {th }}-16^{\text {th }}$ April.

Sabaté, I. (2015b). 'Pan para hoy, hambre para mañana'. Cuando la insostenibilidad del sobre-endeudamiento hipotecario legitima la transgresión de las obligaciones financieras. Comunicación presentada en el I Congreso de la Asociación de Antropólogos Iberoamericanos en Red, Madrid, $7^{\text {th }}-10^{\text {th }}$ July.

Scott, J. (1976). The moral economy of the peasant. Rebellion and Subsistence in Southeast Asia. New Haven: Yale University Press.

Stout, N. (2015). Generating Home. Theorizing the Contemporary Series, Cultural Anthropology Online, Generating Capitalism; Laura Bear, Karen Ho, Anna Tsing, and Sylvia Yanagisako (Eds.), http://www.culanth.org/fieldsights/655-generating-home [29/10/2015]

Thompson, E.P. (1971). The moral economy of the English crowd in the Eighteenth Century. Past and Present, 50, 76-136. doi:10.1093/past/50.1.76 